into a corner where, because of its lack of flexibility, it rannot get more money without developing new lines of research and cannot develop new lines of research without more money. Its greatest need at the moment is for a new director. The job specification calls for a scientist distinguished in his own field who will have the authority to reorganize both the Chester Beatty and the three smaller departments attached to the Institute of Cancer Research. It may be that no scientist of worth will wish to take on an institute which finds itself in such a dilemma. But the challenge would be worth while. Applicants should not delay.

\title{
Cheerful Pugwash at Sochi
}

The nineteenth Pugwash conference at Sochi on the Black Sea from October 22 to 27 seems to have been a successful occasion. Participants included more than 100 scientists from twenty-nine countries. Although. much of the work of the conference lay in familiar Pugwash territory, it appears that the discussions were more than usually cordial. Nobody knows to what extent this may have arisen because the nineteenth conference was the first which has been open to journalists.

A statement issued by the Continuing Committee of Pugwash after the conference deals with a number of familiar topics but also with the problem of Vietnam. It appears that the working group with this problem on its agenda decided that "the complete withdrawal, as quickly as possible, of American troops from South Vietnam is a necessary condition for the establishment of peace in that country". It went on to urge a rapid reduction of the concentration of American troops in South Vietnam and, by doing so, abandoned at least some of the old Pugwash caution which has kept the organization from too direct an involvement with strictly political matters. In Nigeria, Pugwash wants a cease-fire. Although some participants at the conference emerged from the discussion on the Middle East saying "we have fought the Six Day War all over again", in the event the Pugwash statement is for the UN resolution of November 22, 1967, and for a reduction of tension in the Middle East.

In Europe, Pugwash wants to sec a "system for European security and the dissolution of the military blocs". Acknowledging, however, that this is a long term objective, the statement goes on to say that it would like to see short term agreements for the abandonment of the use of force and a reduction of military forces in Europe. In this spirit, the working group dealing with European problems lent its support to the notion of a European security conference, hoping that it would lead to the formation of a permanent body under the aegis of the United Nations. There seems to have been some disagreement about the extent to which the Unitcd States and Canada should be involved in these discussions-a symbol, no doubt, for the political obstacles that would have to be overcome before problems of European security could be considered in isolation. The Sochi Pugwash went on record by asking for a recognition of existing European boundaries, the German Democratic Republic in particular, but had a number of constructive suggestions to make about the greater interchange between East and West in Europe. On Czechoslovakia, however, the Continuing Committee has nothing to say except that there were "conflicting views"--.evidently Czecho- slovakia will cast a shadow over Pugwash for many years to come.

The strongest part of the committee's report is that dealing with nuclear weapons and delivery systems-the problems now to be taken up by the Conference on Strategic Arms Limitations between the United States and the Soviet Union at Helsinki. Pugwash says that the development of antiballistic missiles and multiple independently targetable re-entry vehicles is bound to give another twist to the arms race. Moreover, it says, deployment would upset the calculations on which present strategies are based, with the result that forces would probably be increased in number. This is why the group at Sochi gave an unqualified cheer for the announcement that the SALT talks are due to begin on November 17. There is also some general exhortation in the report on the importance of persuading black sheep to sign both the Non-Proliforation Treaty and the Partial Test-Ban. Treaty.

The working group concerned with strategic arms limitation seems to have considered ways in which the development of ABMs and NIRVs could be stopped, possibly by tacit agreement, by simultaneous unilateral declarations or even by voluntary self-denial in the hope of reciprocal action. To begin with, a moratorium on the testing of both kinds of weapons was held out as a necessary step if comprehensive agreements are eventually to be negotiated.

The statement from the group concerned with arms limitations goes on to say that a substantial reduction in the existing level of armaments would be compatible with effective deterrence. As a part of the package, it considered that more effective means of controlling the production of fissile material ought to be developed within the framework of the International Atomic Energy Agency. It considered that the proposed seabed treaty would be useful if only as a first step. The notion that the partial test-ban should be made comprehensive seems to have been to some members a realistic goal in itself and to others to be a measure to be combined with the SALT talks.

The discussion at Sochi on chemical and biological weapons gave a blessing to the Geneva Protocol of 1925, which prohibits the first use of chemical and biological weapons, but asked that further steps should be taken urgently. One of the problems exercising the group was the degree to which chemical agents could be legitimately used in peacetime and it seems to have agreed that the need for a watertight definition is urgent. At the same time, it wishes to ban the development, production and stockpiling of chemical and biological weapons as well as to encourage rosearch on rapid detection and identification. 